\title{
A Brachial Plexus with an Aberrant Middle Trunk: A Rare Anomaly
}

\author{
Harsh R. Shah ${ }^{1} \quad$ Anupam B. Takwale ${ }^{1} \quad$ Mukund R. Thatte ${ }^{1, \odot}$
}

${ }^{1}$ Department of Plastic Surgery, Bombay Hospital and Institute of Medical Sciences, Mumbai, Maharashtra, India

Indian J Plast Surg 2019;52:364-365

A 30-year-old female presented with left side global brachial plexus injury. On dissecting the affected side, the brachial plexus had a conventional branching pattern with postganglionic complete rupture of $\mathrm{C} 5$ to 6 with poor-quality proximal roots and partial avulsion of $\mathrm{C} 7$ and complete avulsion of $\mathrm{C} 8$ and T1. Considering the findings, the best available option was harvesting the opposite $\mathrm{C} 7$ root.

Infraclavicular exploration on the donor side revealed a lateral cord with no visible anterior division of $\mathrm{C} 7$ joining it and a medial cord. This, thus, accounted for four roots, namely C5, C6, C8, and T1. Further supraclavicular exploration revealed

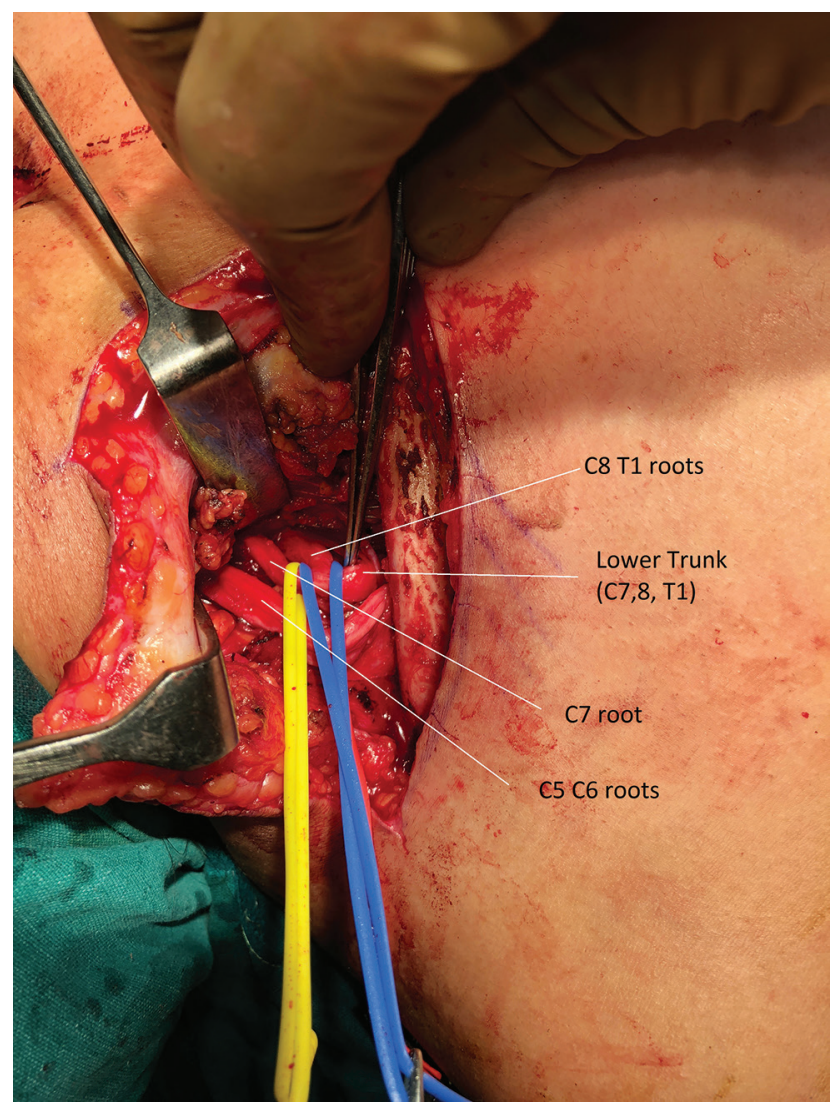

Fig. 1 Clinical picture of the anomalous brachial plexus, superolateral view, showing joining of the C7root to the lower trunk.

Address for correspondence Mukund R Thatte, MS, MCh (plastic surg), Department of Plastic Surgery, Bombay Hospital and Institute of Medical Sciences, Room 215, 2nd Floor, New Wing, Marine Lines, Mumbai, 400020, Maharashtra, India (e-mail: mthatte@gmail.com).

anomalous anatomy of $\mathrm{C} 7$ root. A distinct $\mathrm{C} 7$ root was noted to be uniting with $\mathrm{C} 8$ to $\mathrm{T} 1$ trunk very proximally, instead of continuing as the middle trunk ( - Fig. 1). This anomalous placement of lower three roots caused a difficulty in dissection and identification. Thus, the brachial plexus on normal side had five roots branching to two trunks (upper trunk C5-6 and lower trunk C7-8, T1) (-Fig. 2). The lateral cord was formed from the anterior division of the upper trunk (C5, C6) and medial cord from the anterior division of the lower trunk (C7-8, T1). Thus, the fibers of $\mathrm{C} 7$ went into medial cord instead of the usual lateral cord. The posterior cord was

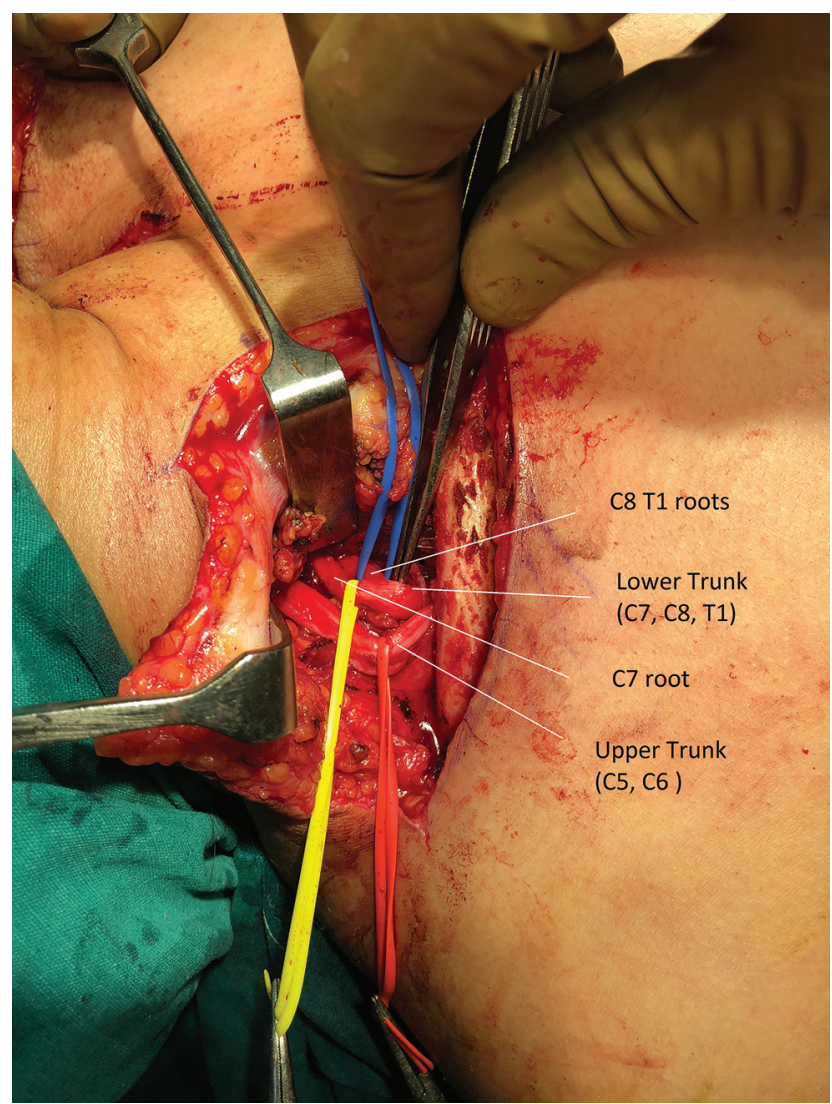

Fig. 2 Superolateral clinical view of the anomalous brachial plexus, showing five roots and two trunks. License terms

published online December 26, 2019
(C2019 Association of Plastic

(ㄷ) (1) $\ominus \circledast$ 

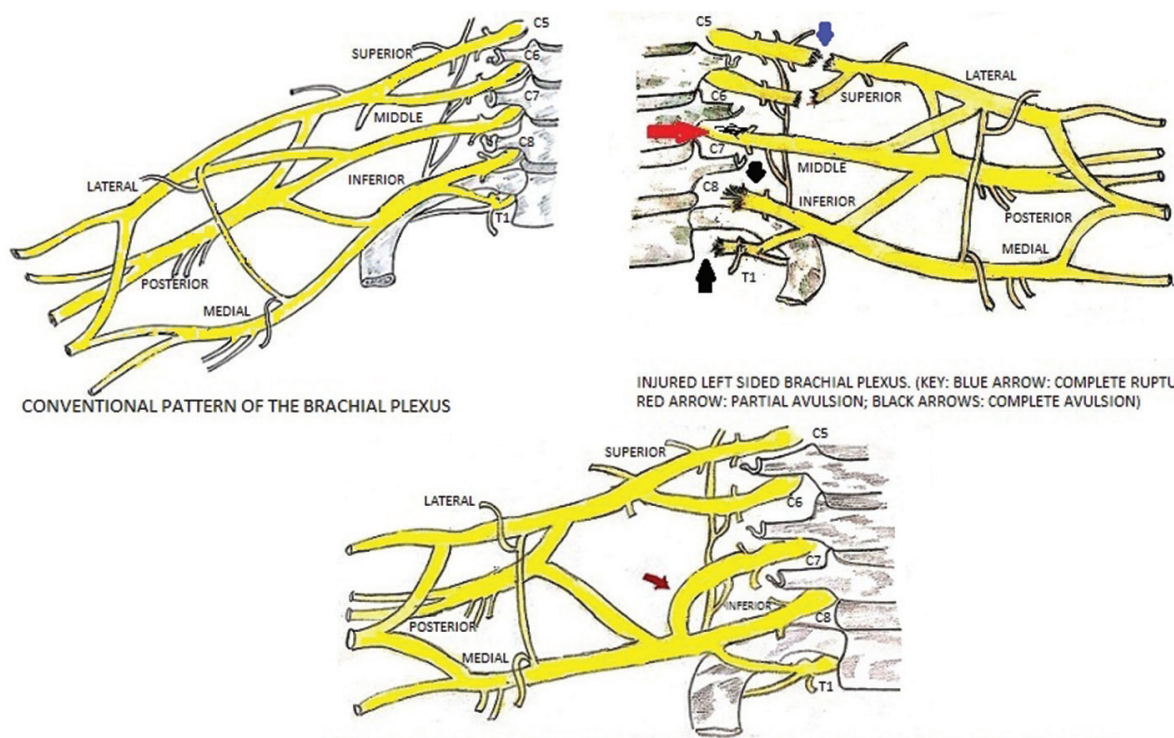

ANATOMICAL VARIATION OF THE C7 ROOT (RED ARROW) ON THE RIGHT SIDE I.E. DONOR SIDE BRACHIAL PLEXUS.

Fig. 3 Schematic diagram, summarizing the findings of the case (clockwise: normal brachial plexus; injured brachial plexus; anomalous brachial plexus).

formed by the fusion of the posterior divisions of the upper (C5-6) and lower (C7-8, T1) trunks ( - Fig. 3).

The abnormal anatomy on the normal side precluded opposite $\mathrm{C7}$ root harvest, because we were unsure of its contributions to various functions and the possible morbidity it could cause. Subsequently, following coaptations were done: XI (spinal accessory nerve)->SSN (suprascapular nerve); C5 $\rightarrow$ C6, C7 $\rightarrow$ C8, T1.

Brachial plexus variations could be influenced by the position of the limb bud in an embryo and the direction of growth of the nerves in the bud. Some variations are similar to the normal brachial plexus anatomy found in different primates, for example, gorillas and chimpanzees. ${ }^{1}$

The common variations in brachial plexus formation are the prefixed and postfixed plexuses. Inferior trunk absence has been found to be more than the absence of upper trunk. ${ }^{2}$ The absence of the middle trunk has been less frequently observed. Upper trunk formation by ventral rami of the C5, C6, and C7 roots with subsequent absence of middle trunk has been found in four cases. ${ }^{3-5}$ While a very few cases in the past have reported the absence of middle trunk along with inferior trunk formation from lower three roots. ${ }^{6,7}$

Such anomalous brachial plexus can often give rises to atypical presentation of Klumpke's paralysis. This rare case of abnormal brachial plexus anatomy is one of the first cases to be reported in a surgical patient, rather than being a cadaveric study.

\section{Source(s) of Support}

Nil.

\section{Presentation at a Meeting}

Nil.

\section{Conflict of Interest}

Nil.

\section{Acknowledgment}

Nil.

\section{References}

1 Miller R. Comparative studies upon the morphology and distribution of the brachial plexus. Am J Anat 1993;54(1):143-166

2 Uysal II, Şeker M, Karabulut AK, Büyükmumcu M, Ziylan T. Brachial plexus variations in human fetuses. Neurosurgery 2003;53(3):676-684, discussion 684

3 Matejcik V. Aberrant formation and clinical picture of brachial plexus from the point of view of a neurosurgeon. Bratisl Lek Listy 2003;104(10):291-299

4 Nayak S, Somayaji N, Vollala VR, et al. A rare variation in the formation of the upper trunk of the brachial plexus - a case report. Neuroanat 2005;4:37-38

5 Patel M, Yadav A, Srivastava M, Dixit A. Absence of middle trunk of brachial plexus: an uncommon variation. J Evol Med Dent Sci 2013;2(39):7468-7471

6 Singla RK, Sharma RK, Shree B. A two trunked brachial plexus: a case report. J Clin Diagn Res 2013;7(4):704-705

7 Abhilasha P, Gupta C, D'Souza A. Cadaveric study of supraclavicular part of brachial plexus. IJARS 2018;7(4):AO41-AO44 